pag

Business School

WORKING PAPER SERIES

Working Paper

2014-295
Policy uncertainty and performance characteristics of sustainable investments across regions around the global financial crisis

Hooi Hooi Lean

Duc Khuong Nguyen

http://www.ipag.fr/fr/accueil/la-recherche/publications-WP.html

IPAG Business School

184, Boulevard Saint-Germain

75006 Paris

France 


\title{
Policy uncertainty and performance characteristics of sustainable investments across regions around the global financial crisis
}

\author{
Hooi Hooi Lean \\ Economics Program, School of Social Sciences \\ Universiti Sains Malaysia, Malaysia \\ hooilean@usm.my \\ Duc Khuong Nguyen* \\ IPAG Lab, IPAG Business School, France \\ duc.nguyen@ipag.fr \\ * Corresponding author: IPAG Business School, 184, Boulevard Saint-Germain, 75006 Paris, France. Phone: \\ +33(0)1 53633600 - Fax: +33(0)145444046
}

\begin{abstract}
We analyze the performance characteristics of sustainable investments over the period 2004-2013. Our unconditional analysis shows that the sustainable portfolios, represented by the Dow Jones Sustainability Indices (DJSI) for the global and three regional markets, experience lower Sharpe ratios than their corresponding conventional portfolios. The conditional analysis indicates some evidence of significant effects of the recent crisis on sustainable investment return and volatility, while the US policy uncertainty only affects returns in two regions (Asia Pacific and North America) during the crisis period. We finally find a relative decoupling of sustainable investing from the overall market system during crisis times.
\end{abstract}

Keywords: sustainable investments; performance; EGARCH; economic policy uncertainty. JEL classifications: G11 


\section{Introduction}

Socially responsible investment (SRI) is an increasingly important area in finance. The term SRI refers to investment that incorporates environmental, social, governance factors (Ghoul and Karam, 2007; Renneboog et al., 2008). The history of SRI may date back to 1758 where the Quaker Philadelphia strictly forbidden their member from taking part in slave and weapon trading (Renneboog et al., 2008). However, the first formal discussion and analysis of SRI companies emerged in the 1970s by Moskowitz (1970). The SRI becomes more and more popular as well as a new dedicated investment strategy because its objective is in line with the "doing well while doing good" statement of Hamilton et al. (1993). ${ }^{1}$ Doing "good" refers to positive impact from the activities that are supported by SRI investors. This positive impact can create values to the world because the companies and governments are operating ethically and responsibly.

Over the recent years, a growing number of investors feel good for not supporting the socalled "sinful" activities and many governments have shown their interest in implementing SRI in their countries. For example, Belgium, Italy, Sweden and United Kingdom required the pension funds to disclose the degree of participation in social, ethical and environmental aspects (Renneboog et al., 2008).

A considerable amount of literature has tested Hamilton et al. (1993)'s statement by comparing the performance of SRI portfolios and funds with that of conventional and benchmark investments. From a theoretical point of view, many argued that "doing good" usually come at a cost that the portfolio will achieve lower returns because the SRI portfolio can be considered as a less diversified portfolio owing to limited investment opportunities. However, most empirical studies have found no significant difference in the performance between SRI and conventional portfolios (e.g., Hamilton et al., 1993; Bauer et al., 2007; Kempf and Osthoff,

\footnotetext{
${ }^{1}$ Moreover, according to the statistics from Eurosif's 2008 and 2010 reports, the amount of SRI assets around the world is increasing from year to year.
} 
2008; Gil-Bazo et al., 2009; Climent and Soriano, 2011; Humphrey and Lee, 2011). In particular, several studies show that SRI investments (funds/portfolios) outperformed the conventional ones (e.g., Alam and Rajjaque, 2010; Consolandi et al., 2009; Fernandez-Izquierdo and Matallin-Saez, 2008; Gil-Bazo et al., 2010; Lyn and Zychowicz, 2010). Adler and Kritzman (2008), Jones et al. (2008) and Renneboorg et al. (2008) find the reverse evidence.

This study also focuses on the SRI performance issues by investigating the return and volatility of SRI indices from three major regions (Asia Pacific, Europe and North America) as well as the world index. ${ }^{2}$ Specifically, our objective is to examine how the SRI copes with the onset of the recent global financial crisis 2008-2009 in terms of market performance and how their performance is compared with that of conventional investments. In particular, we consider the effect of the US economic policy uncertainty index (EPUI) on the distributional characteristics of stock returns. This index, introduced by Baker et al. (2012), broadly reflects the uncertainty about economic, monetary and fiscal policies, and is now commonly viewed as an indicator of economic risk. Since the United States plays a leading role in the global economy, changes in the EPUI may affect consumption, production, company investments, and stock prices in various regions. It is thus expected that the high level of uncertainty depresses stock returns. At the empirical analysis, we consider the Dow Jones Sustainability Indices (DJSI) for different regions as benchmarks for SRI as well as their conventional counterparts. The finding of this study will provide investors and policymakers with a better understanding of the SRI performance across the regions in time of crisis.

Our research is thus broadly related to the strand of literature regarding the performance characteristics of SRI indices being viewed as synthetic SRI portfolios (e.g., Schröder, 2004, 2007; Collison et al., 2008; Consolandi et al., 2008; Copp et al., 2010; Managi et al., 2012). The common consensus is that the SRI indices do at least as well as the conventional ones in

\footnotetext{
${ }^{2}$ As noted by Schröder et al. (2007), the study on stock market indices has advantage in terms of transaction cost. Moreover, market timing skill and stock selection skill of fund managers are not required to be studied at the index level.
} 
terms of market performance. For example, Consolandi et al. (2008) study the performance of Dow Jones Stoxx Sustainability Index which tracks the top $20 \%$ of European companies drawn from the largest 600 companies in the Euro Stoxx index and compare it to the Surrogate Complementary Index which represents the remaining $80 \%$ of 600 companies in Dow Jones Euro Stoxx 600 Index. They show limited difference in the performance between the two indices. Managi et al. (2012) detect no significant difference in return and risk between the SRI index and the conventional index in the United States, the United Kingdom and Japan.

The rest of the article is organized as follows. Section 2 explains the data and methodology. Section 3 reports and discusses the empirical findings. Section 4 concludes the article.

\section{Data and methodology}

The SRI indices and corresponding conventional indices are collected from the Dow Jones website and Datastream, respectively. ${ }^{3}$ The Dow Jones SRI indices include Dow Jones Sustainability Index World (DJSIWD), Dow Jones Sustainability Index Asia Pacific (DJSIAP), Dow Jones Sustainability Index Europe (DJSIEU) and Dow Jones Sustainability Index North America (DJSINA). The conventional indices are Dow Jones Global Index World (DJGIWD), Dow Jones Global Index Asia Pacific (DJGIAP), Dow Jones Global Index Europe (DJGIEU) and Dow Jones Global Index America (DJGIAM). Our sample period from January 1, 2004 to August 30, 2013 is selected to cover the recent global financial crisis. Return series are calculated by taking the difference in the logarithm between two consecutive index prices.

Methodologically, we use an extended market model to examine the risk-return trade-off of the sustainable and conventional portfolio investments. A dummy variable $\left(D_{t}\right)$ is introduced to capture the effects of the 2008-2009 global financial crisis (GFC). $D_{t}$ takes a value

\footnotetext{
${ }^{3}$ http://www.sustainability-indices.com/
} 
of one during the crisis period and zeros otherwise. Referring to the US Financial Stress Index, the period from September 15, 2008 to May 30, 2009 is identified as the GFC period.

The excess return market model with dummy variable is as follows:

$\left(R_{i t}-R_{f}\right)=\beta_{0}+\beta_{1}\left(R_{m t}-R_{f}\right)+\beta_{2} D_{t}+\varepsilon_{t}$

where $R_{i t}, R_{m t}$, and $R_{f}$ refer to the returns on the sustainable and conventional investment portfolios (indices), the benchmark market portfolio, and the risk free asset (US T-bill). Depending on the SRI indices under consideration, the benchmark market portfolio can be the Dow Jones Global Index for the world equity market or the corresponding regional equity market.

In order to account for the impact of the US policy uncertainty on the SRI performance, we estimate the following augmented market model:

$\left(R_{i t}-R_{f}\right)=\alpha_{0}+\alpha_{1}\left(R_{m t}-R_{f}\right)+\alpha_{2} \Delta \ln (E P U I)+D_{t}\left[\delta_{0}+\delta_{1}\left(R_{m t}-R_{f}\right)+\delta_{2} \Delta \ln (E P U I)\right]+\varepsilon_{t}$

As it is common to empirical studies focusing on conditional volatility of financial returns, we also use the GARCH-type model to accommodate the important stylized facts of portfolio returns (e.g., volatility clustering, asymmetric volatility, and leverage effects). For this purpose, we estimate various univariate GARCH specifications including the standard GARCH, IGARCH, EGARCH and TGARCH, and use the commonly-used information criteria (AIC and BIC) to select the best-suited volatility process. Our results are in favor of the EGARCH model for most return series we consider. ${ }^{4}$ Consequently, we retain this volatility specification to ease the comparison of results across markets.

Formally, the EGARCH model developed by Nelson (1991) specifies the conditional variance equation by explicitly accommodating asymmetric shock to volatility. This effect, which is also known as leverage effect, exists when bad news contribute more in volatility than

\footnotetext{
${ }^{4}$ The results of the volatility specification tests can be made available under request addressed to the corresponding author.
} 
good news. By taking into logarithm, the leverage effect is found to be exponential. The EGARCH model is defined as:

$$
\log \left(\sigma_{t}^{2}\right)=\omega_{0}+\omega_{1} \log \left(\sigma_{t-1}^{2}\right)+\omega_{2}\left|\frac{\varepsilon_{t-1}}{\sigma_{t-1}}\right|+\omega_{3} \frac{\varepsilon_{t-1}}{\sigma_{t-1}}
$$

The leverage effect can be determined by testing the nullity of $\omega_{3}$. If $\omega_{3} \neq 0$, the impact is asymmetric. If $\omega_{3}<0$, the bad news will increase the volatility than the good news do, leading to leverage effects.

It is worth noting that we estimate our empirical model for the full sample period and three subperiods including the pre-GFC, GFC and post-GFC. This procedure enables us to examine difference in the volatility structure across different episodes of the global financial crisis.

\section{Findings and discussions}

\subsection{Unconditional analysis}

Table 1 shows the descriptive statistics of daily returns on SRI and conventional indices. Panel A indicates that the returns on SRI indices are lower than those on conventional indices over full sample period with relatively similar standard deviations. The daily Sharpe ratios, as measured by the ratio of mean return to standard deviation, are positive for all indices and SRI indices underperform the corresponding conventional ones except the Europe region. Within the SRI universe, the Asia Pacific region has the highest Sharpe ratio, whereas the European region has the lowest Sharpe ratio. The underperformance of the SRI indices over the whole period is confirmed by the results reported in Panels B-D for the pre-GFC, GFC and post-GFC subperiods. It is important to note that all the markets exhibit negative Sharpe ratio during the recent global financial crisis, and become positive in the post-GFC period.

All the return series exhibit negative skewness and display excess kurtosis. It means that their probability distributions are skewed to the left and have a leptokurtic behavior with the tails being fatter than those of the corresponding normal distributions. These signs clearly 
reject the normality of return series under consideration, which is confirmed by the JarqueBera test for normality. We also compute the Engle (1982) test for conditional heteroscedasticity with 6 lags. The results, not reported here for concision purpose, show that all the return series exhibit ARCH effects, suggesting the suitability of the GARCH-type model in modeling the stylized facts of conditional volatility.

Table 1: Descriptive statistics of daily returns

\begin{tabular}{|c|c|c|c|c|c|c|}
\hline & Mean $(\%)$ & Std. Dev. (\%) & Skewness & Kurtosis & Sharpe ratio & $\mathrm{JB}$ \\
\hline \multicolumn{7}{|c|}{ Panel A: Full period } \\
\hline DJSIWD & 0.0092 & 0.0121 & -0.2815 & 11.2102 & 0.0076 & $7116.8^{+}$ \\
\hline DJSIAP & 0.0129 & 0.0141 & -0.3394 & 8.7457 & 0.0092 & $3517.5^{+}$ \\
\hline DJSIEU & 0.0063 & 0.0126 & -0.1294 & 10.5548 & 0.0050 & $6004.7^{+}$ \\
\hline DJSINA & 0.0093 & 0.0120 & -0.4112 & 13.7579 & 0.0078 & $12232.5^{+}$ \\
\hline DJGIWD & 0.0160 & 0.0109 & -0.4930 & 11.6022 & 0.0147 & $7878.0^{+}$ \\
\hline DJGIAP & 0.0151 & 0.0124 & -0.4479 & 9.0631 & 0.0122 & $3947.3^{+}$ \\
\hline DJGIEU & 0.0069 & 0.0166 & -0.0832 & 8.9148 & 0.0041 & $3679.3^{+}$ \\
\hline DJGIAM & 0.0185 & 0.0129 & -0.4623 & 13.5747 & 0.0143 & $11840.6^{+}$ \\
\hline \multicolumn{7}{|c|}{ Panel B: Pre-GFC period } \\
\hline DJSIWD & 0.0163 & 0.0079 & -0.2213 & 6.0759 & 0.0206 & $493.7^{+}$ \\
\hline DJSIAP & 0.0206 & 0.0121 & -0.2610 & 5.0613 & 0.0171 & $231.2^{+}$ \\
\hline DJSIEU & 0.0106 & 0.0094 & -0.3600 & 7.2412 & 0.0113 & $946.1^{+}$ \\
\hline DJSINA & 0.0032 & 0.0080 & -0.3631 & 5.3076 & 0.0039 & $299.2^{+}$ \\
\hline DJGIWD & 0.0209 & 0.0072 & -0.3388 & 4.6137 & 0.0289 & $156.6^{+}$ \\
\hline DJGIAP & 0.0214 & 0.0110 & -0.4272 & 5.7330 & 0.0194 & $419.2^{+}$ \\
\hline DJGIEU & 0.0291 & 0.0107 & -0.3397 & 7.7925 & 0.0272 & $1197.8^{+}$ \\
\hline DJGIAM & 0.0179 & 0.0086 & -0.3193 & 5.0170 & 0.0209 & $228.8^{+}$ \\
\hline \multicolumn{7}{|c|}{ Panel C: GFC period } \\
\hline DJSIWD & -0.1527 & 0.0280 & -0.0482 & 4.1693 & -0.0545 & $10.6^{+}$ \\
\hline DJSIAP & -0.1040 & 0.0299 & -0.1437 & 4.3335 & -0.0347 & $14.3^{+}$ \\
\hline DJSIEU & -0.1671 & 0.0278 & 0.1145 & 4.3945 & -0.0601 & $15.4^{+}$ \\
\hline DJSINA & -0.1435 & 0.0302 & -0.0796 & 4.0054 & -0.0475 & $7.9^{+}$ \\
\hline DJGIWD & -0.1410 & 0.0258 & -0.1576 & 3.9945 & -0.0548 & $8.4^{+}$ \\
\hline DJGIAP & -0.0739 & 0.0257 & -0.2106 & 4.6923 & -0.0288 & $23.4^{+}$ \\
\hline DJGIEU & -0.1667 & 0.0340 & 0.1304 & 4.2501 & -0.0491 & $12.6^{+}$ \\
\hline DJGIAM & -0.1578 & 0.0324 & -0.1024 & 3.9648 & -0.0488 & $7.5^{+}$ \\
\hline \multicolumn{7}{|c|}{ Panel D: Post-GFC period } \\
\hline DJSIWD & 0.0283 & 0.0116 & -0.1944 & 5.4153 & 0.0244 & $276.8^{+}$ \\
\hline DJSIAP & 0.0239 & 0.0118 & -0.3415 & 4.2045 & 0.0202 & $88.7^{+}$ \\
\hline DJSIEU & 0.0303 & 0.0115 & -0.0660 & 5.8203 & 0.0264 & $368.7^{+}$ \\
\hline DJSINA & 0.0416 & 0.0101 & -0.4093 & 6.1513 & 0.0410 & $490.3^{+}$ \\
\hline DJGIWD & 0.0367 & 0.0100 & -0.4005 & 5.8622 & 0.0368 & $408.6^{+}$ \\
\hline DJGIAP & 0.0229 & 0.0102 & -0.4351 & 4.4941 & 0.0225 & $138.3^{+}$ \\
\hline DJGIEU & 0.0112 & 0.0175 & -0.0698 & 5.2215 & 0.0064 & $229.1^{+}$ \\
\hline DJGIAM & 0.0485 & 0.0111 & -0.4778 & 6.7339 & 0.0438 & $687.0^{+}$ \\
\hline
\end{tabular}

Note: Full Period: 1/1/2004 - 30/8/2013; Pre-GFC: 1/1/2004 - 14/9/2008; GFC: 15/9/2008 - 31/5/2009; PostGFC: $1 / 6 / 2009-30 / 8 / 2013$. JB refers to the empirical statistics of the Jarque-Bera test for normality. ${ }^{+}$denotes the rejection of the null hypothesis of normality at the $1 \%$ level.

The correlation among the considered indices over the whole period, reported in Table 2, indicates that the returns on SRI and conventional stock market indices of the same region are 
highly positively correlated except the North American region where the highest correlation with the world sustainable investment market reaches 0.34 . For example, the correlation between the sustainable and conventional segments of the Dow Jones World Index reaches 0.96. The results for the GFC subperiod, not reported here for concision purpose, shows a slight increase in the correlations across all regions except the North American region.

Table 2: Correlation matrix of sample returns

\begin{tabular}{llllllll}
\hline & DJSIWD & DJSIAP & DJSIEU & DJSINA & DJGIWD & DJGIAP & DJGIEU \\
\hline DJSIWD & 1.0000 & & & & & & \\
DJSIAP & 0.4972 & 1.0000 & & & & & \\
DJSIEU & 0.8983 & 0.3490 & 1.0000 & & & & \\
DJSINA & 0.3447 & 0.0606 & 0.2780 & 1.0000 & & & \\
DJGIWD & 0.9616 & 0.5022 & 0.8285 & 0.3634 & 1.0000 & & \\
DJGIAP & 0.5152 & 0.9811 & 0.3755 & 0.0688 & 0.5281 & 1.0000 & 1.0000 \\
DJGIEU & 0.9462 & 0.4105 & 0.8788 & 0.3167 & 0.8540 & 0.4306 & 0.6212 \\
DJGIAM & 0.7758 & 0.1696 & 0.6490 & 0.3868 & 0.8913 & 0.1904 & 0.000 \\
\hline
\end{tabular}

\subsection{Conditional analysis}

Table 3 reports the estimation results of the excess market model. As it can be seen, all the constant terms are significant at the $1 \%$ level with a positive value for the world market and Asia Pacific region sustainable investment indices, and negative value for the European and North American sustainable investment indices. This finding suggests that there is an increasing tendency of SRI returns at the world level, and that over the long term the SRI investments in Asia Pacific region outperform those in Europe and North America. Regarding the estimated betas which represent the sensitivity of the SRI returns to the market-wide source of risk (systematic risk), we find that the components of the sustainability indices for World (DJSIWD) and Asia Pacific (DJSIAP) markets constitute aggressive portfolios in view of the beta values that exceed one. Inversely, the DJSINA and DJSIEU market indices are conservative portfolios.

Table 3: Estimation results of the market model (full sample period)

\begin{tabular}{lccc}
\hline Index & $\beta_{0}$ & $\beta_{1}$ & $\beta_{2}$ \\
\hline DJSIWD & $0.0002^{* * *}$ & $1.0496^{* * * *}$ & -0.0003 \\
DJSIAP & $0.0006^{* * *}$ & $1.0894^{* * *}$ & $-0.0008^{* * *}$ \\
DJSIEU & $-0.0018^{* * *}$ & $0.7183^{* * *}$ & $0.0012^{* *}$ \\
DJSINA & $-0.0032^{* * *}$ & $0.5095^{* * *}$ & $0.0023^{* *}$ \\
\hline Note: & and ${ }^{* * *}$ denote significance at the 5\% and 1\% levels, respectively.
\end{tabular}


A close look at the dummy variable which represents the effect of the recent global financial crisis on SRI returns, we see that all sustainable investment indices are affected by the crisis except the world sustainable index where the associated coefficient is insignificant. While the recent crisis leads to lower the performance of DJSIAP market, it has a positive effect on the returns of the two other regions (DJSIEU and DJSINA). In a related study, Ang and Lean (2013) find consistent evidence that the performance of SRI funds in Luxembourg is higher during the global financial crisis.

Table 4 reports the estimation results of the augmented market model where not only the crisis effects but also the impacts of the US economic policy uncertainty (EPUI) on the SRI performance are taken into account. Several interesting results can be noted. First, similar to the market model estimations, the constant terms are significant in all cases with a positive value for the world and Asian Pacific sustainable indices, and a negative value for European and North American sustainable indices.

Second, the DJSIWD and DJSIAP constituents form aggressive portfolios and outperform the market portfolio's average returns. It is worth noting that the returns on the DJSIWD are independent of the market-wide movements during the crisis period. For other sustainable indices, the betas are much smaller during normal times than during the crisis period. This result seems to suggest that SRI portfolios may provide a cushion against the increasing risk in stock markets during turbulent times.

Finally, the changes in the US economic policy uncertainty index only have a predictive power on SRI returns of two regions, Asia Pacific and North America, during the global financial crisis. Higher uncertainty leads to lower the SRI returns in North America, but increase those in Asia Pacific. Our results for sustainable investments thus do not confirm the theoretical predictions and the general empirical consensus that policy uncertainty depresses stock returns. For instance, Antonakakis et al. (2013) study the dynamic correlations among 
S\&P 500 market returns, stock market's implied volatility, and policy uncertainty index of Baker et al. (2012), and find a negative conditional correlation between market returns and policy uncertainty over time. Kang and Ratti (2013) investigate the effects of oil price shocks and economic policy uncertainty on stock returns in the United States, and find real stock returns decline in response to an unexpected increase in policy uncertainty. The positive impact that the US policy uncertainty index has on stock returns in the Asia Pacific may be due to the high economic growth of the main regional countries like China and India, which is an important driver of stock market performance.

Table 4: Augmented Market Model Estimation Results (full sample period)

\begin{tabular}{|c|c|c|c|c|c|c|}
\hline Index & $\alpha_{0}$ & $\alpha_{1}$ & $\alpha_{2}$ & $\delta_{0}$ & $\delta_{1}$ & $\delta_{2}$ \\
\hline DJSIWD & $0.0003^{* * *}$ & $1.0524^{\text {***** }}$ & -0.0001 & -0.0003 & -0.0096 & -0.0008 \\
\hline DJSIAP & $0.0004^{* * *}$ & $1.0704^{* * *}$ & $2.53 \times 10^{-5}$ & $-0.0006^{* * *}$ & $0.0796^{* * *}$ & $0.0012^{* *}$ \\
\hline DJSIEU & $-0.0019^{* * *}$ & $0.7052^{* * *}$ & -0.0001 & $0.0013^{* * *}$ & $0.0495^{* * *}$ & -0.0011 \\
\hline DJSINA & $-0.0010^{* * *}$ & $0.8493^{* * *}$ & -0.0003 & -0.0012 & $-0.9629^{* * *}$ & $-0.0063^{* * *}$ \\
\hline
\end{tabular}

Notes: ${ }^{* *}$ and ${ }^{* * * *}$ denote significance at the $5 \%$ and $1 \%$ levels, respectively.

We now turn to the analysis of conditional volatility of SRI portfolios. Table 5 reports the estimation results of the EGARCH model using the augmented market model as the conditional mean equation. The results indicate that the EGARCH model successfully captures the dynamics of conditional volatility of different SRI portfolios as the estimates of the ARCH and GARCH coefficients are highly significant across different periods around the global financial crisis. The important magnitude of the GARCH coefficient $\left(\omega_{1}\right)$ suggests the high persistence of conditional volatility over time. The EGARCH model fails, however, in explaining the volatility patterns of the SRI return series for the Asia Pacific region during the global financial crisis. As to the volatility leverage effect, it is not dominant and only found to be significant for SRI returns in North America in the GFC and post-GFC periods and for SRI returns in Europe in the post-GFC period. It is worth noting that positive shocks have greater impact on conditional volatility than negative shocks in the post-GFC period for the SRI returns in North America. 
Table 5: Estimation results of the EGARCH Model

\begin{tabular}{|c|c|c|c|c|}
\hline Panel A: Full Period: 1/1/2004 - 30/8/2013 & $\omega_{0}$ & $\omega_{1}$ & $\omega_{2}$ & $\omega_{3}$ \\
\hline DJSIWD & $-0.3313^{* * *}$ & $0.9844^{* * *}$ & $0.1897^{* * * *}$ & -0.0073 \\
\hline DJSIAP & $-0.1920^{* * *}$ & $0.9910^{* * *}$ & $0.1089^{* * *}$ & 0.0023 \\
\hline DJSIEU & $-0.1529^{* * *}$ & $0.9913^{* * *}$ & $0.0823^{* * *}$ & -0.0004 \\
\hline DJSINA & $-0.2440^{* * *}$ & $0.9943^{* * *}$ & $0.2348^{* * *}$ & -0.0049 \\
\hline \multicolumn{5}{|l|}{ Panel B: Pre-GFC: $1 / 1 / 2004-14 / 9 / 2008$} \\
\hline DJSIWD & $-0.8348^{* * *}$ & $0.9470^{* * *}$ & $0.2492^{* * *}$ & -0.0086 \\
\hline DJSIAP & $-0.1784^{* * *}$ & $0.9913^{* * *}$ & $0.0948^{* * * *}$ & -0.0069 \\
\hline DJSIEU & $-0.2169^{* *}$ & $0.9845^{* * *}$ & $0.0726^{* * * *}$ & 0.0165 \\
\hline DJSINA & $-0.2202^{* * *}$ & $0.9964^{* * *}$ & $0.2419^{* * *}$ & -0.0165 \\
\hline \multicolumn{5}{|l|}{ Panel C: GFC: $15 / 9 / 2008-31 / 5 / 2009$} \\
\hline DJSIWD & $-4.6386^{* *}$ & $0.5839^{* * *}$ & $0.6857^{* * * *}$ & 0.0774 \\
\hline DJSIAP & -12.2080 & -0.1575 & -0.2247 & 0.0486 \\
\hline DJSIEU & $-3.6639^{* *}$ & $0.6275^{* * *}$ & $0.3354^{* *}$ & -0.1120 \\
\hline DJSINA & $-0.3013^{* *}$ & $0.9590^{* * *}$ & -0.0021 & $-0.1697^{* * * *}$ \\
\hline \multicolumn{5}{|l|}{ Panel D: Post-GFC: $1 / 6 / 2009-30 / 8 / 2013$} \\
\hline DJSIWD & $-1.2258^{* * * *}$ & $0.9108^{* * *}$ & $0.2128^{* * * *}$ & $0.0629^{* * * *}$ \\
\hline DJSIAP & $-0.9118^{* * *}$ & $0.9333^{* * *}$ & $0.1444^{* * *}$ & 0.0172 \\
\hline DJSIEU & $-1.4134^{* * *}$ & $0.8785^{* * *}$ & $0.1600^{* * *}$ & $-0.0510^{* *}$ \\
\hline DJSINA & $-3.5999^{* * *}$ & $0.7371^{* * *}$ & $0.2192^{* * *}$ & $0.0712^{* * *}$ \\
\hline
\end{tabular}

Note: ${ }^{* * *}$ and ${ }^{* * *}$ denote significance at the $5 \%$ and $1 \%$ levels, respectively.

Figure 1. Time-varying volatility

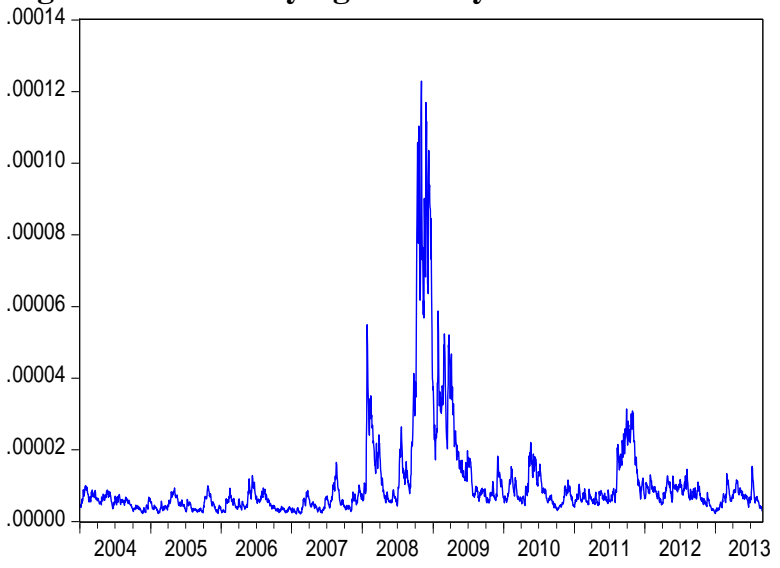

DJSIWD

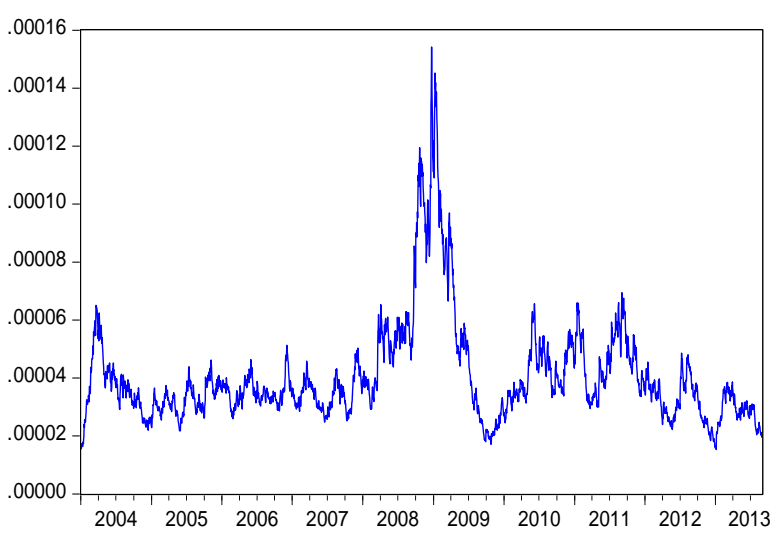

DJSIEU
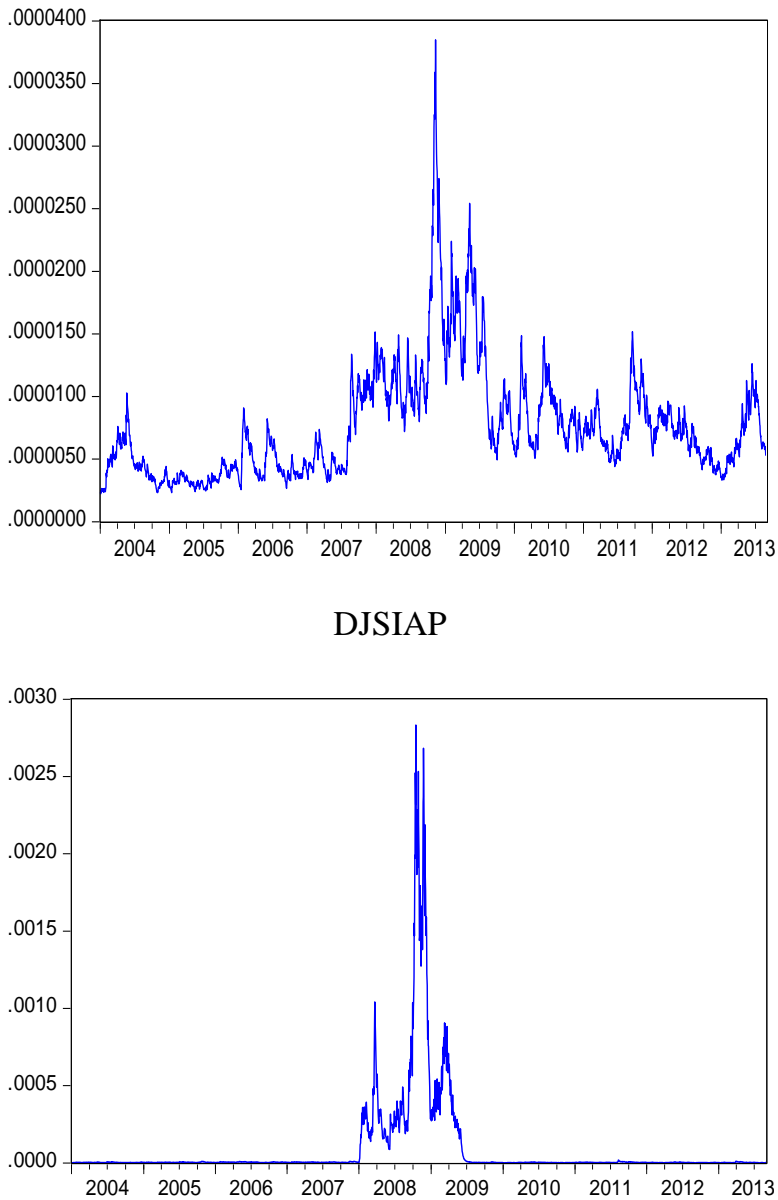

DJSINA 
Figure 1 presents the time-varying volatility for full sample period in all regions. We can see a high degree of volatility during the GFC period for all the return series we consider. Asia Pacific region has the lowest volatility compared to the other regions. North America shows an obvious pattern that the high volatility is gathered in the GFC period while other periods are very small and close to zero. These graphs illustrate that the volatility for the SRI indices varies through time and the GFC brings higher risk to the investors.

\section{Conclusion}

This article examines the performance and volatility of Dow Jones Sustainability Indices over the period of 2004-2013. We particularly analyze how SRI returns and volatility react to the global financial crisis 2008-2009 and the US economic policy uncertainty. Our results show that both return and volatility of sustainable investment portfolios are generally affected by the recent global financial crisis. There is also evidence to suggest that SRI returns in Asian Pacific and North American regions react significantly to changes in the US economic policy uncertainty index. Finally, while we observe an increased in the conditional volatility of sustainable investment indices during the recent crisis period, their connection to the systematic is lower during the same period. This relative decoupling of the overall market system in times of crisis can be considered as a good performance characteristic of "sustainable" investors who like "doing well while doing good". 


\section{References}

Adler, T., Kritzman, M., 2008. The cost of socially responsible investing. Journal of Portfolio Management 35(1), 52-56.

Alam, N., Rajjaque, M.S., 2010. Shariah-compliant equities: Empirical evaluation of performance in the European market during credit crunch. Journal of Financial Services Marketing, 15(3), 228-240.

Ang, W.R., Lean, H.H., 2013. Market timing ability of socially responsible investing funds in Luxembourg, in Financial Aspects of Recent Trends in the Global Economy Volume II, Rajmund Mirdala (Eds), Craiova: ASERS Publishing, 128-135.

Basso, A., Funari, S., 2013. Constant and variable returns to scale DEA models for socially responsible investment funds. European Journal of Operational Research, In Press, Corrected Proof.

Bauer, R., Derwall, J., Otten, R., 2007. The ethical mutual fund performance debate: New evidence from Canada. Journal of Business Ethics 70(2), 111-124.

Beal, D.J., Goyen, M., Phillips, P., 2005. Why do we invest ethically? Journal of Investing 14(3), 66-77.

Bollerslev, T., 1986. Generalized autoregressive conditional heteroskedasticity. Journal of Econometrics 31, 307-327

Climent, F.P., 2011. Green and good? The investment performance of US environmental mutual funds. Journal of Business Ethics, 103(2), 275-287.

Collison, D.J., Cobb, G., Power, D.M., Stevenson, L.A., 2008. The financial performance of the FTSE4Good indices. Corporate Social Responsibility \& Environmental Management 15(1), 14-28.

Consolandi, C., Jaiswal-Dale, A., Poggiani, E., Vercelli, A., 2009. Global standards and ethical stock indexes: The case of the Dow Jones Sustainability Stoxx Index. Journal of Business Ethics 87, 185-197.

Copp, R., Kremmer, M.L., Roca, E., 2010. Should funds invest in socially responsible investments during downturns? Financial and legal implications of the fund manager's dilemma. Accounting Research Journal 23(3), 254-266

Fernandez-Izquierdo, A., Matallin-Saez, J., 2008. Performance of ethical mutual funds in Spain: sacrifice or premium? Journal of Business Ethics 81(2), 247-260.

Ferson, W. E., Schadt, R.W., 1996. Measuring fund strategy and performance in changing economic conditions. Journal of Finance 51(2), 425-461.

Flower, S.J., Hope, C., 2007. Incorporating sustainable business practices into company strategy. Business Strategy and the Environment 16(1), 26-38.

Ghoul, W., Karam, P., 2007. MRI and SRI mutual funds: A comparison of Christian, Islamic (morally responsible investing), and socially responsible investing (SRI) mutual funds. Journal of Investing 16(2), 96-102.

Gil-Bazo, J., Ruiz-Verdú, P., Santos, A., 2010. The performance of socially responsible mutual funds: The role of fees and management companies. Journal of Business Ethics 94(2), 243-263. 
Glosten, L.R., Jagannathan, R., Runkle, D.E., 1993. On the relation between the expected value and the volatility of the nominal excess return on stocks. Journal of Finance 48, 17791801 .

Hamilton, S., Jo, H., Statman, M., 1993. Doing well while doing good? The investment performance of socially responsible mutual funds. Financial Analysts Journal 49(6), 62.

Henriksson, R.D., Merton, R.C., 1981. On market timing and investment performance II: Statistical procedures for evaluating forecasting skills. Journal of Business 54(4), 513-533.

Humphrey, J., Lee, D., 2011. Australian socially responsible funds: Performance, risk and screening intensity. Journal of Business Ethics 102(4), 519-535.

Ivashina, V., Scharfstein, D., 2010. Bank lending during the financial crisis of 2008. Journal of Financial Economics 97(3), 319-338.

Jones, S., van der Laan, S., Frost, G., Loftus, J., 2008. The investment performance of socially responsible investment funds in Australia. Journal of Business Ethics 80(2), 181-203.

Kempf, A., Osthoff, P., 2007. The effect of socially responsible investing on portfolio performance. European Financial Management 13(5), 908-922.

Lyn, E.O., Zychowicz, E.J., 2010. The impact of faith-based screens on investment performance. Journal of Investing 19(3), 136-143.

Managi, S., Okimoto, T., Matsuda, A., 2012. Do socially responsible investment indexes outperform conventional indexes? Applied Financial Economics 22(18), 1511-1527.

Moskowitz, M.R., 1972. Choosing socially responsible stocks. Business \& Society Review 1, 71-75.

Nelson, D.B., 1991. Conditional heteroskedasticity in asset returns: A new approach. Econometrica 59, 347-370.

Ortas, E., Moneva, J.M., Salvador, M., 2012. Does socially responsible investment equity indexes in emerging markets pay off? Evidence from Brazil. Emerging Markets Review 13(4), 581-597.

Renneboog, L., Ter Horst, J., Zhang, C., 2008. Socially responsible investments: Institutional aspects, performance, and investor behavior. Journal of Banking and Finance 32(9), 17231742 .

Roca, E, Wong, S.H., Tularam, G.A., 2010. Are socially responsible investment markets worldwide integrated? Accounting Research Journal 23(3), 281-301.

Schröder, M., 2004. The performance of socially responsible investment: Investment funds and indices. Financial Markets and Portfolio Management 18(2), 122-142.

Schröder, M., 2007. Is there a difference? The performance characteristics of SRI equity indices. Journal of Business Finance \& Accounting 34(1/2), 331-348.

Treynor, J.L., Mazuy, K.K., 1966. Can mutual funds outguess the market? Harvard Business Review 44(4), 131-136. 